\title{
Vascular Endothelial Growth Factor Is an Essential Molecule for Mouse Kidney Development: Glomerulogenesis and Nephrogenesis
}

\author{
Yasunori Kitamoto, Hiroshi Tokunaga, and Kimio Tomita \\ Third Department of Internal Medicine, Kumamoto University School of Medicine, Kumamoto 860, Japan
}

\begin{abstract}
Homeostasis of body fluid is maintained by the kidneys, which contain two million glomeruli for blood filtration. A glomerulus is formed by growth of Bowman's capsule harmonized with a capillary during kidney development. The vascular endothelial growth factor (VEGF) is an essential angiogenic cytokine, and VEGF deficiency is known to be fatal in mice in early embryonic stages. As secretions of VEGF from cultured kidneys vary according to developmental stages, the role of VEGF in kidney development was studied in vivo by blocking the endogenous VEGF activity with antibody in newborn mice, in which most organs are already developed but kidneys are still developing. The antibody-treated animals showed normal growth but systemic edema. Vessel formation in the superficial renal cortex was disturbed, nephrogenic areas were diminished, and the number of developing nephrons decreased significantly. Many abnormal glomeruli, lacking capillary tufts, were observed in the antibody-treated mice, and VEGF expression in their Bowman's capsule showed a compensatory increase. These results suggest that VEGF mediates communication between the Bowman's capsule and capillary endothelial cells for developing a glomerulus as well as promoting nephrogenesis. In conclusion, VEGF is likely to be an essential molecule for kidney development, and especially for glomerulogenesis. (J. Clin. Invest. 1997. 99:2351-2357.) Key words: renal organogenesis - glomerular development • organ culture e endogenous vascular endothelial growth factor • neutralizing antibody
\end{abstract}

\section{Introduction}

The kidney is an essential organ that evolved as protovertebrates migrated into fresh water to keep their internal environment of high osmolarity from surrounding freshwater. In mammals, a permanent kidney originates from metanephric mesenchyme and starts to develop by invasion of the ureteric bud. Reciprocal induction between the epithelial cells of ureteric bud and undifferentiated mesenchymal cells promotes nephrogenesis. Various growth factors (1-5) seem to work at different stages of this process. When comma-shaped bodies

Address correspondence to Yasunori Kitamoto, Third Department of Internal Medicine, Kumamoto University School of Medicine, 1-1-1 Honjo, Kumamoto 860, Japan. Phone: 81-96-373-5164; FAX: 81-96366-8458; E-mail: yasunori@kaiju.medic.kumamoto-u.ac.jp

Received for publication 8 October 1996 and accepted in revised form 7 March 1997.

J. Clin. Invest.

(C) The American Society for Clinical Investigation, Inc.

0021-9738/97/05/2351/07 \$2.00

Volume 99, Number 10, May 1997, 2351-2357 are formed, they are accompanied by capillaries (6) for further glomerulogenesis. Thus, the glomerulus is generated by the harmonized development of the Bowman's capsule, a part of the nephron, with a capillary. Only a limited number of studies $(7,8)$ have been reported on this glomerulogenesis at the molecular level and the major signal that induces this glomerular development has not yet been clarified.

Vascular endothelial growth factor $(\mathrm{VEGF})^{1}$ is an angiogenic cytokine that is important in developmental blood vessel formation (9-12) as well as tumor angiogenesis (13). Typically, VEGF is secreted from epithelial cells and binds to its receptor tyrosine kinases on endothelial cells flt- 1 and flk-1, stimulating blood vessel growth. As VEGF- or its receptor-deficient mice die at early embryonic stages (9-12) due to impaired vessel formation, the role of VEGF in organogenesis cannot be addressed in these knockout mice.

In kidneys of embryonic to adult humans $(14,15)$ and mice $(16,17)$, the message of VEGF is detected in epithelial cells of glomeruli, while the message of VEGF receptors is expressed in endothelial cells of glomerular and peritubular capillaries. The VEGF message is also observed in proximal and distal convoluted tubules of the adult rat (18). Thus, VEGF seems to play an important role for development and maintenance of glomerular integrity; however, no functional studies have been done to prove this hypothesis to date.

To clarify the role of VEGF in kidney development, in vitro secretion of VEGF from kidneys at different developmental stages was first examined in this study, and then the effect of antibody that blocks endogenous VEGF activity on kidney development in vivo was studied.

\section{Methods}

Organ culture. 14 kidneys were harvested from seven embryos or newborns on 12,13,14, and 15 days post coitum (d.p.c.) and 0 days after birth and cultured over a membrane filter that was submerged in $1 \mathrm{ml}$ of serum-free medium (19) at $37^{\circ} \mathrm{C}$ in air containing $5 \% \mathrm{CO}_{2}$ in a high humidity incubator. After a 2-d incubation, medium was collected and stored at $-30^{\circ} \mathrm{C}$ until measurement of VEGF. Fluorescent enzyme-immunoassay (Toagosei, Tsukuba, Japan) (20) was used to quantify the amount of VEGF. Data were calibrated as mouse VEGF $_{164}$, divided by wet weight of a kidney, and expressed as an average of three experiments.

Administering anti-VEGF neutralizing antibody to mice. Neutralizing antibody to recombinant human $\mathrm{VEGF}_{165}$ was given from Genentec Inc. (South San Francisco, CA) as antiserum. $1 \mathrm{ml}$ of the serum should neutralize $5 \mu \mathrm{g}$ of $\mathrm{VEGF}_{165}$ in human umbilical vein endothelial cell proliferation assay (data not shown). The antiserum was administered to three male mice weighing $1.5 \mathrm{~g}$ on average, intraperitoneally on $0,2,4$, and $5 \mathrm{~d}$ after birth with $100 \mu \mathrm{l}$ per dose. Normal rabbit serum was administered to three littermates as a control. Mice were killed on the day after the last injection of the antibody. Harvested kidneys were examined with light microscopy and electronmi-

1. Abbreviations used in this paper: d.p.c., days post coitum; VEGF, vascular endothelial growth factor. 
croscopy, and also studied with immunohistochemistry using various antibodies. Other organs including heart, lung, spleen, liver, and brain were also observed with light microscopy.

Routine histology and immunohistochemistry. For light microscopy, kidneys were fixed with $4 \%$ paraformaldehyde in $0.1 \mathrm{M}$ phosphate buffer, $\mathrm{pH} 7.2$, for $7 \mathrm{~d}$ and embedded in paraffin, or were rapidly frozen in liquid nitrogen. 4- $\mu \mathrm{m}$ paraffin sections were stained with hematoxylin and eosin. Immunohistochemistry was performed (21) on $8-\mu \mathrm{m}$ paraffin sections or 8 - $\mu \mathrm{m}$ frozen sections. Paraffin sections were dewaxed, treated for 20 min with $1 \% \mathrm{H}_{2} \mathrm{O}_{2} /$ methanol, and then incubated overnight with a goat polyclonal antibody against human VEGF ${ }_{165}$ (1:300; R\&D Systems, Inc., Minneapolis, MN) and processed further by avidin-biotin-complex peroxidase method (Vector Laboratories, Inc., Burlingame, CA). To detect localization of the administered antibody, frozen sections were fixed in acetone for $10 \mathrm{~min}$, and then incubated for $2 \mathrm{~h}$ with a peroxidase-conjugated goat polyclonal antibody against rabbit IgG (1:100; Organon Teknika-Cappel, Durham, NC). Immunoreactivity was visualized with peroxidase reaction in 3,3'-diaminobenzidine tetrahydrochloride (DAB) and $\mathrm{H}_{2} \mathrm{O}_{2}$ solution. To detect precise localization of the administered antibody, double immunostaining was performed, where type IV collagen was stained to outline the framework of the vasculature. Frozen sections were first incubated for $2 \mathrm{~h}$ with a peroxidase-conjugated goat polyclonal antibody against rabbit IgG (1:100; Organon Teknika-Cappel) and peroxidase reaction was performed in DAB and $\mathrm{H}_{2} \mathrm{O}_{2}$ solution with $1 \% \mathrm{NiSO}_{4}$ and $1 \% \mathrm{CoCl}_{2}$ to give a black color. Next, sections were incubated overnight with a rabbit polyclonal antibody against mouse type IV collagen (1:1,200; LSLaboserv, Giessen, Germany). A peroxidase-conjugated goat polyclonal antibody against rabbit IgG was used as a second antibody. Peroxidase reaction was performed in DAB and $\mathrm{H}_{2} \mathrm{O}_{2}$ solution to give a brown color. Slides were lightly counterstained with hematoxylin.

Quantitative analysis of morphological changes. Histological observation was carried out by two authors independently and the average values were used. Data were given by observation of nine sections from three control and nine sections from three antibody-treated mice, respectively, that were prepared by cutting kidneys along their longitudinal axes to show maximal cutting areas.
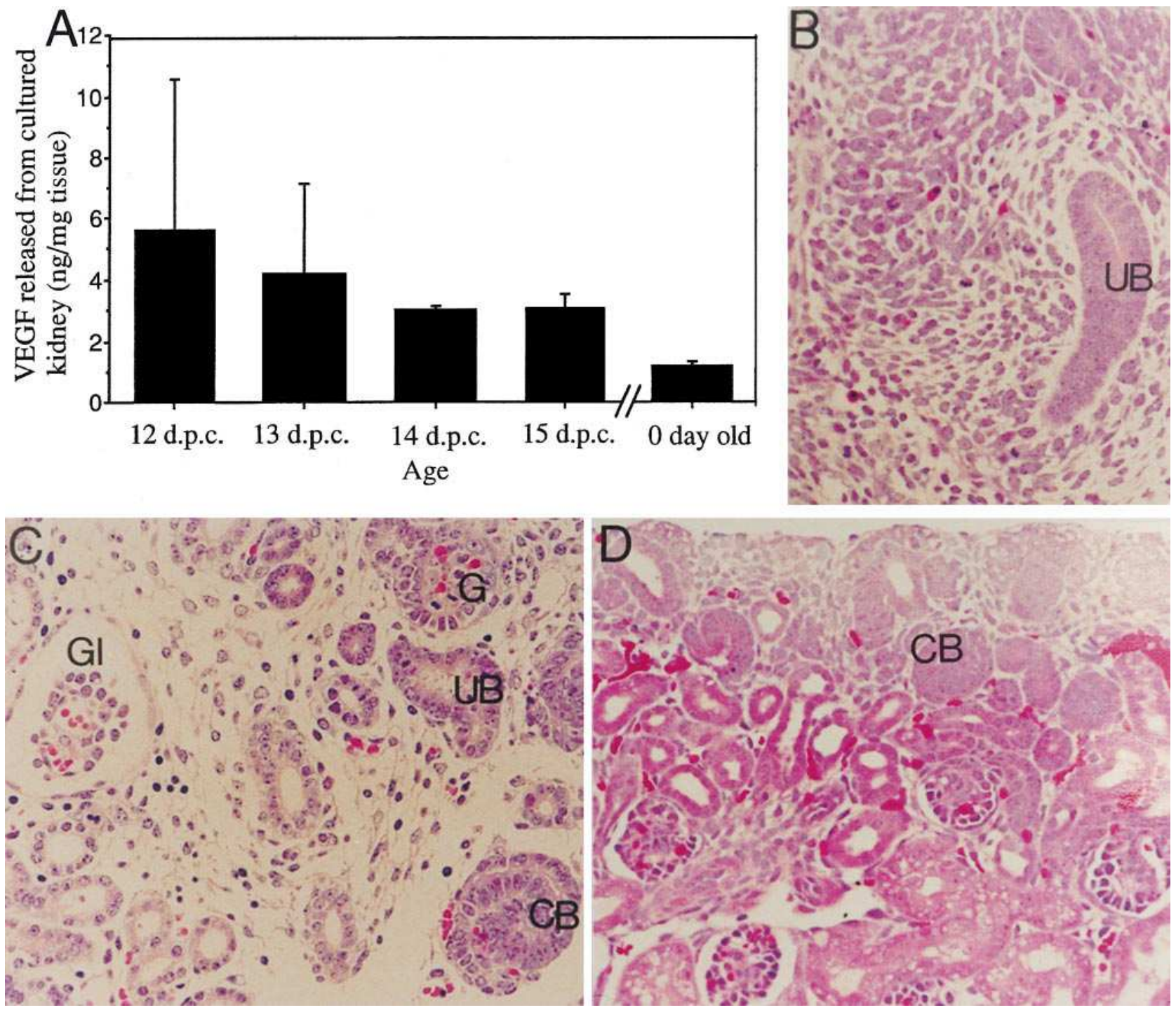

Figure 1. Secretion of VEGF from developing kidneys. (A) VEGF release per milligram of kidney tissue in organ culture. (B-D) Hematoxylin and eosin staining $(80 \times) .(B)$ Embryonic kidney at 12 d.p.c. Nucleated erythrocytes are noted in the capillary. $(C)$ Embryonic kidney at 15 d.p.c. Developing nephrons and glomeruli $(G$, and $G l)$ are observed. Gl is more developed than G. $(D)$ The kidney of a newborn mouse. Basophilic area of the extreme cortex is nephrogenic area. UB, ureteric bud; $\mathrm{CB}$, comma-shaped body. 
Electronmicroscopy. Small tissue slices of fresh kidneys were fixed in a half Karnovsky's fixative containing $2.5 \%$ glutaraldehyde and $2 \%$ paraformaldehyde in $0.1 \mathrm{M}$ phosphate buffer, $\mathrm{pH} 7.2$, and then embedded in epoxy resin. Sections of 40- and 90-nm thick were cut on an ultramicrotome, double stained with uranyl acetate and lead citrate, and observed with a transmission electronmicroscopy (JEM-100CX; JEOL Ltd., Akishima, Tokyo).

\section{Results}

VEGF secretion from cultured kidneys. Cultured kidneys of $12,13,14$, and 15 d.p.c. and $0 \mathrm{~d}$ after birth released 5.6, 4.2, 3.0, 3.0 , and $1.2 \mathrm{ng}$ of VEGF, respectively, per $1 \mathrm{mg}$ of tissue during a 2-d culture period (Fig. $1 A$ ). Secretion of VEGF tends to de- cline as kidney development proceeds and the amount of VEGF released by kidneys of the newborn mice is less than half that of the others. Morphological studies are shown in Fig. $1, B-D$. At 12 d.p.c., undifferentiated mesenchymal cells, the ureteric bud, and capillaries are observed in metanephros (Fig. $1 \mathrm{~B})$. At 15 d.p.c., the metanephros mostly consists of developing nephrons and glomeruli (Fig. $1 C$ ). At birth, developing nephrons, including comma- and S-shaped bodies, are observed only in the extreme cortex; i.e., nephrogenic area (Fig. 1 $D)$. Well developed glomeruli are seen in juxtamedullary cortex.

Blocking of endogenous VEGF activity. Antibody-treated mice were edematous on the fifth day after birth (Fig. $2 A, b$ ),
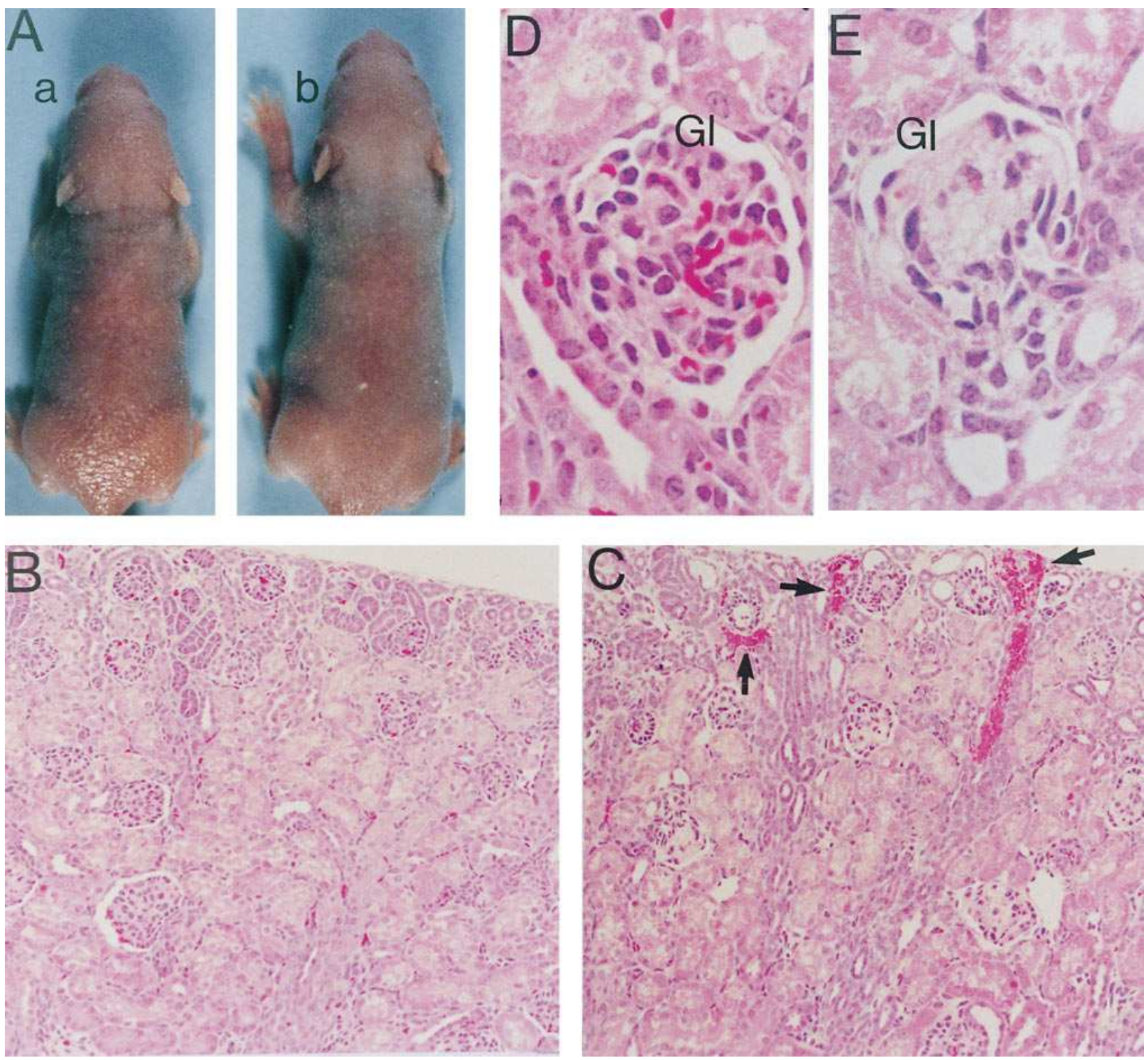

Figure 2. VEGF is essential for kidney development. $(A)$ The antibody-treated mouse $(b)$ is edematous. A skin fold around the neck and skin furrows over the hips are seen in the control mouse $(a)$, but not in the antibody-treated mouse $(b)$. $(B-E)$ Hematoxylin and eosin staining of the kidney. $(B)$ In the control, nephrogenic area is conserved $(40 \times)$. (C) In the antibody-treated mouse, nephrogenic area is diminished. Several blood vessels (arrows) in the superficial cortex are congested. Abnormal glomeruli with decreased cellularity and increased extracellular matrix are observed $(40 \times)$. (D) Higher magnification of a glomerulus in $B(160 \times)$. (E) Higher magnification of an abnormal glomerulus in $C(160 \times)$. Gl, glomerulus. 
although there was no significant difference in body weight between control and antibody-treated mice (which averaged 5.36 and $5.53 \mathrm{~g}$, respectively). There were no clear signs of cardiac failure, including pulmonary congestion or ventricular dilatation. In control mice, developing nephrons and developing glomeruli were observed in the superficial cortex and well developed glomeruli were observed in the juxtamedullary cortex (Fig. $2 \mathrm{~B}$ ). On the contrary, in the antibody-treated mice, nephrogenic area was diminished and the number of glomeruli decreased. The number of comma- plus S-shaped bodies per section was $4.6 \pm 3.4$ in control and $0.3 \pm 0.5$ in antibody-treated mice. The total number of matured glomeruli per section was $118 \pm 25$ in control and $83 \pm 9$ in antibody-treated mice. A number of abnormal glomeruli with poor cellularity and increased extracellular matrices were observed in the antibody-treated mice (Fig. $2 C$ ) and, remarkably, several glomeruli lacked capillary tufts (Fig. 2 E). Glomeruli without capillary tufts occupied $3.9 \pm 2.2 \%$ of the total matured glomeruli in control and $29.0 \pm 7.4 \%$ of the total in antibody-treated mice. On the other hand, no significant changes were observed in nonglomerular vasculatures of the antibody-treated mice as compared with the controls. Glomeruli accompanied by arteriole in section occupied $35 \pm 13 \%$ and $42 \pm 7 \%$ of the matured glomeruli in control and antibody-treated mice, respectively. Several small blood vessels that otherwise should have been directed to developing glomeruli were congested in the superficial cortex, including the nephrogenic area in the antibody-treated mice. No morphological changes were observed in the heart, lung, brain, liver, or spleen using hematoxylin and eosin staining (data not shown).

Glomerular microstructure. With an electronmicroscope, developing glomeruli with dual basement membranes (22) were observed in the antibody-treated mice (Fig. $3 A$ ). Immature capillaries with narrow slitlike lumen were also observed in the glomeruli of antibody-treated mice (Fig. $3 \mathrm{~B}$ ). These capillary structures were hardly seen in the glomeruli of control mice. An amorphous substance surrounded by podocytes (Fig. 3 C) was found only in the glomeruli of antibody-treated mice. This may correspond to the abnormal glomerular structure without capillary tuft as shown by light microscopy (Fig. 2E).

$V E G F$ expression. According to immunohistochemical studies using antihuman VEGF antibody, VEGF was detected only in distal tubules in the controls (Fig. 4 A). In contrast, VEGF was clearly detected in Bowman's capsules and proximal tubules as well as distal tubules in the antibody-treated mice (Fig. 4, $B$ and $C$ ). Interestingly, VEGF was observed both in parietal epithelial cells of the Bowman's capsule of a developing glomerulus that was waiting for its capillary formation and in visceral epithelial cells of the Bowman's capsule of a more developed glomerulus (Fig. 4C).

Localization of the administered antibody. Administered anti-VEGF antibody localized specifically at glomeruli (Fig. $4 E$ ). Double immunostaining of rabbit IgG and type IV collagen clarified that the antibody specifically localized on the glomerular endothelial cells (Fig. $4 G$ ). However, the administered antibody was not detected in the other renal blood vessels (Fig. $4 E$ ).

\section{Discussion}

Development of the vascular system plays a central role in a number of physiological and pathological processes, including
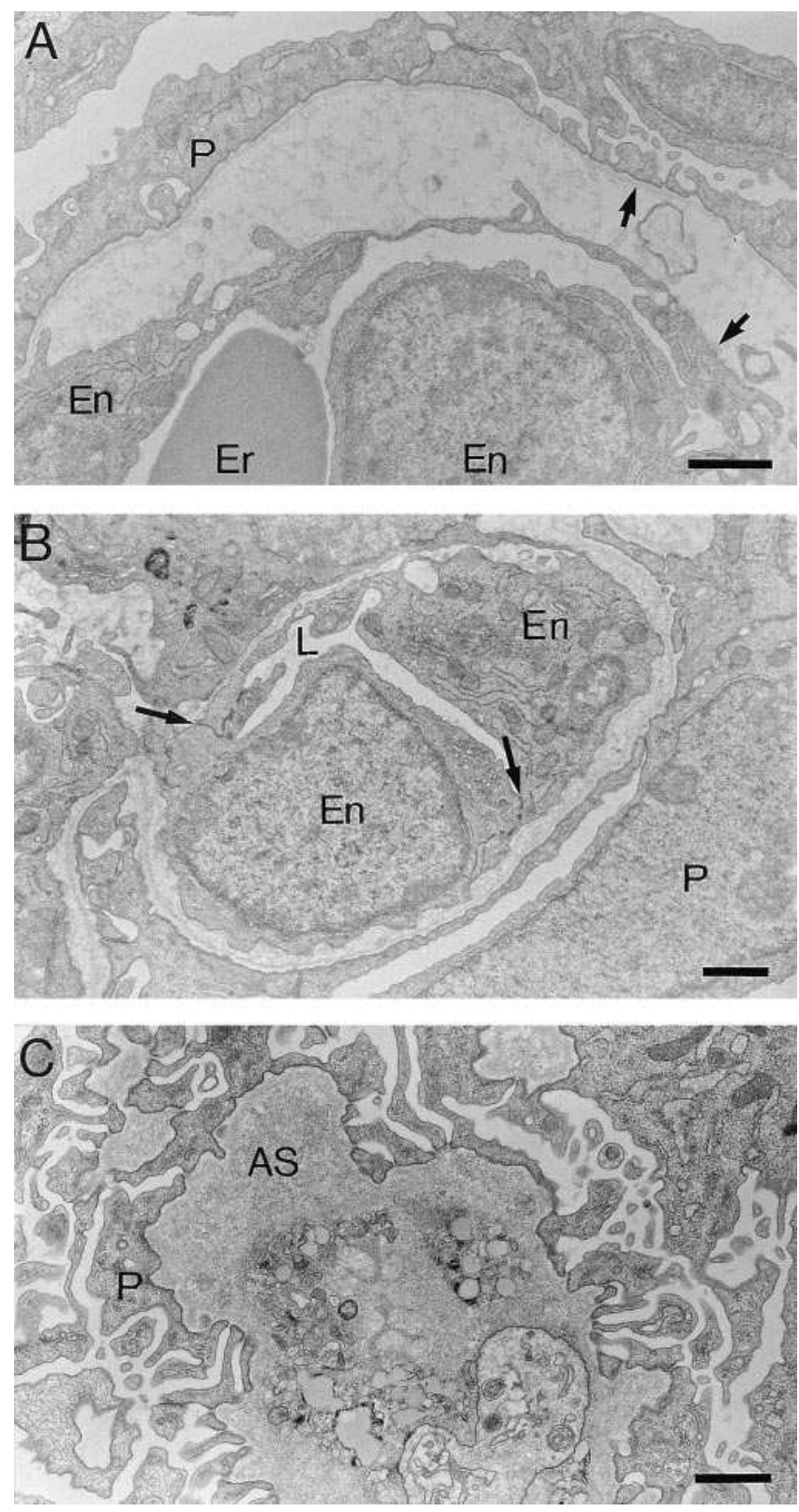

Figure 3. Electronmicrographs of the glomeruli of the antibodytreated mouse. (A) Dual basement membranes (arrows). (B) An immature capillary with a slitlike lumen $(L)$. Junctional complexes are shown by arrows. $(C)$ Amorphous substance surrounded by podocytes. Scale bars in $A-C$ show $1 \mu \mathrm{m}$. Er, erythrocyte; En, endothelial cell; $\mathrm{P}$, podocyte; AS, amorphous substance.

organogenesis, wound healing, and tumor growth. VEGF is an angiogenic cytokine without which the embryo dies at an early stage because no vascular system develops $(9,10)$. Thus, VEGF is regarded as essential in developmental vessel formation. However, its role in organogenesis is still unknown and is only suggested indirectly from the expression pattern of VEGF and its receptors (16). The role of VEGF in the organogenesis of the kidney, which is a vascular-rich organ and starts to develop at a later embryonic stage, was studied directly by blocking endogenous VEGF activity in vivo.

The metanephros, origin of the permanent kidney, appears 

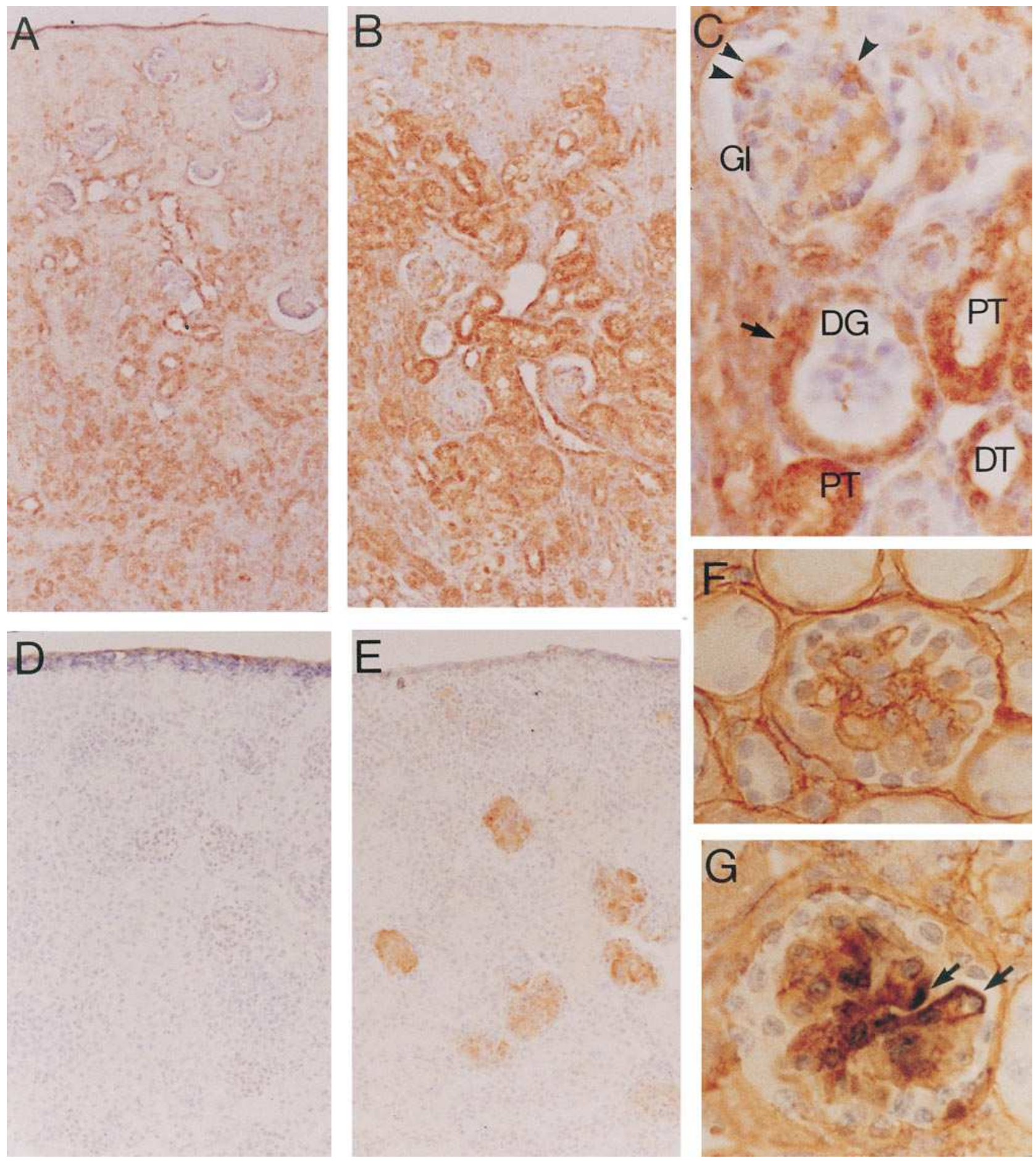

Figure 4. Immunohistochemical staining of endogenous VEGF and anti-VEGF antibody administered. VEGF is stained in $A-C$. $(A)$ In the control, VEGF is detected only in distal tubules $(40 \times)$. $(B)$ In the antibody-treated mouse, VEGF is stained in proximal tubules and Bowman's capsules as well as distal tubules $(40 \times)$. ( $C$ ) Higher magnification of $B(160 \times)$. VEGF is detected in parietal epithelial cells (arrow) of the Bowman's capsule in a developing glomerulus $(D G)$, just before its capillary formation. In a more developed glomerulus $(G l)$, VEGF is detected also in visceral epithelial cells (arrowheads) of the Bowman's capsule. VEGF is also localized at proximal tubules $(P T)$, as well as distal tubules $(D T)$. $(D$ and $E$ ) The administered antibody is stained immunohistochemically by antirabbit immunoglobulins. $(D)$ Background in the control (40 $\times$ ). $(E)$ The administered antibody is detected at glomeruli of the antibody-treated mouse $(40 \times)$. $(F$ and $G)$ The administered antibody and type IV collagen are double-stained in black and brown, respectively $(400 \times) .(F)$ In the control, only type IV collagen is stained. $(G)$ The administered antibody is stained in black (arrow) on the glomerular endothelial cells of the antibody-treated mouse. 
around 11 d.p.c. in the mouse and its development continues until 2 wk after birth. The capacity for isolated kidneys to secrete VEGF in vitro seems to correlate well with their potency to develop in vivo (Fig. $1 A$ ). To test a hypothesis that VEGF is a critical molecule for kidney development in mice, endogenous VEGF activity was blocked by rabbit polyclonal antibody to human $\mathrm{VEGF}_{165}$. Development of the kidney was impaired in glomerulogenesis as well as nephrogenesis by the antibody administration as shown in Fig. 2. Glomerular development was retarded characteristically through impaired capillary network formation. Congested blood vessels in superficial cortex are also results of retarded and/or disoriented formation of the capillaries that otherwise should have been directed to glomeruli (Fig. 2 C). Diminished nephrogenesis observed in antibodytreated kidneys (Fig. $2 C$ ) may be an indirect effect resulting from disturbed blood vessel formation in the nephrogenic area. As expression of VEGF receptors has not been reported in immature mesenchymal cells or ureteric bud epithelial cells $(14,15)$, direct effect of VEGF on those cells seems to be less probable. These changes in the kidney likely resulted in the impaired water handling and edema observed in the antibodytreated mice (Fig. $2 A, b$ ). Judging from these serious morphological changes caused by blocking endogenous VEGF activity, VEGF should be a critical molecule mediating kidney development, especially glomerulogenesis.

A significant number of endogenous VEGF molecules should have been captured by the administered antibody and inactivated. On the other hand, the rest of the VEGF should have escaped from this trapping and reacted with its receptors, which are reported to be highly expressed in the glomerular endothelial cells of developing kidneys $(14,15)$, and stimulated the cells. The receptor-bound VEGF should have reacted with the administered anti-VEGF antibody, which was shown immunohistochemically to localize on the glomerular endothelial cells (Fig. 4, $E$ and $G$ ). However, stimulation of the endothelial cells by VEGF that escaped from the trapping was not enough to perform normal glomerular development, and VEGF expression in Bowman's capsule greatly increased from an undetectable to a clearly visible level with immunohistochemistry as shown in Fig. 4, $A-C$. The upregulation of VEGF seems to be a compensatory response of epithelial cells to reconstruct a glomerulus and is triggered by the hypoxic milieu surrounding the cells (23), resulting from poor vascularity in the glomerulus. This strongly supports a hypothesis that Bowman's capsule synthesizes and secretes VEGF to stimulate capillary endothelial cells to develop a glomerulus. In tubules, upregulation of VEGF is probably initiated also by the hypoxic signal resulting from poor peritubular vascularity, which is downstream of the glomerular capillary. In distal tubules, VEGF expression may be necessary to maintain the fenestration of capillary endothelial cells (16).

The expected upregulation of the receptors, together with the great compensatory increase of VEGF observed in this study, suggests that VEGF requirement for glomerular development is much stricter than for other vessels. In a developing glomerulus, endothelial cells must proliferate quickly to form a very dense capillary network in limited time, which may be equivalent to the explosive development of the vascular system at early embryonic stage, where the VEGF requirement has been shown to be very strict $(9,10)$. Thus, among the many vessels, the glomerular capillary was specifically affected by the antibody. Alternatively, another angiogenic factor might be involved in the formation of the other blood vessels that were not affected by the antibody.

In conclusion, VEGF has been clarified to mediate the organogenesis of the kidney, especially glomerulogenesis, as a communication molecule between Bowman's capsule and capillary endothelial cells in paracrine fashion. This glomerulogenesis is unique in its strict requirement of VEGF. Moreover, this study may lead to a new approach to regenerating a glomerulus, which is important for the study of organogenesis of the kidney as well as for the therapy of renal diseases.

\section{Acknowledgments}

We are grateful to Dr. Napoleone Ferrara (Genentec Inc., South San Francisco, CA) for neutralizing antibody. We thank Dr. Mitsuya Hanatani (Toagosei, Tsukuba, Japan) for measurement of VEGF. We thank Miss Noriko Teramoto and Miss Yasuyo Hayashida for technical assistance. We acknowledge Dr. Kuniya Abe and Dr. Ken-ichi Iyama (Kumamoto University School of Medicine), Dr. Kazuya Yoshinaga (Miyazaki Medical College, Kiyotake, Japan), Dr. Christine Sorenson and Dr. J. Evan Sadler (Washington University School of Medicine, St. Louis, MO), and Dr. Qingyu Wu (Berlex, San Francisco, CA) for their comments and suggestions. We also thank Dr. Yasuo Uehara (Kumamoto University School of Medicine) for his encouragement.

This work was supported by a Grant-in-Aid for Scientific Research in Japan (07807107 and 07457242) and a grant from Houan-sha Foundation.

\section{References}

1. Santos, O.F.P., and S.K. Nigam. 1993. HGF-induced tubulogenesis and branching of epithelial cells is modulated by extracellular matrix and TGF- $\beta$. Dev. Biol. 160:293-302.

2. Ritvos, O., T. Tuuri, M. Erämaa, K. Sainio, K. Hildén, L. Saxén, and S.F. Gilbert. 1995. Activin disrupts epithelial branching morphogenesis in developing glandular organs of the mouse. Mech. Dev. 50:229-245.

3. Perantoni, A.O., L.F. Dove, and I. Karavanova. 1995. Basic fibroblast growth factor can mediate the early inductive events in renal development. Proc. Natl. Acad. Sci. USA. 92:4696-4700.

4. Sariola, H., M. Saarma, K. Sainio, U. Arumäe, J. Palgi, A. Vaahtokari, I. Thesleff, and A. Karavanov. 1991. Dependence of kidney morphogenesis on the expression of nerve growth factor receptor. Science (Wash. DC). 254:571-573.

5. Rogers, S.A., G. Ryan, and M.R. Hammerman. 1991. Insulin-like growth factors I and II are produced in the metanephros and are required for growth and development in vitro. J. Cell Biol. 113:1447-1453.

6. Abrahamson, D.R. 1985. Origin of the glomerular basement membrane visualized after in vivo labeling of laminin in newborn rat kidneys. J. Cell Biol. 100:1988-2000.

7. Levéen, P., M. Pekny, S. Gebre-Medhin, B. Swolin, E. Larsson, and C. Betsholtz. 1994. Mice deficient for PDGF B show renal, cardiovascular, and hematological abnormalities. Genes Dev. 8:1875-1887.

8. Soriano, P. 1994. Abnormal kidney development and hematological disorders in PDGFß-receptor mutant mice. Genes Dev. 8:1888-1896.

9. Carmeliet, P., V. Ferreira, G. Breier, S. Pollefeyt, L. Kieckens, M. Gertsenstein, M. Fahrig, A. Vandenhoeck, K. Harpal, C. Eberhardt, et al. 1996. Abnormal blood vessel development and lethality in embryos lacking a single VEGF allele. Nature (Lond.). 380:435-439.

10. Ferrara, N., K. Carver-Moore, H. Chen, M. Dowd, L. Lu, K.S. O'Shea, L. Powell-Braxton, K.J. Hillan, and M.W. Moore. 1996. Heterozygous embryonic lethality induced by targeted inactivation of the VEGF gene. Nature (Lond.). 380:439-442.

11. Shalaby, F., J. Rossant, T.P. Yamaguchi, M. Gertsenstein, X.-F. Wu, M.L. Breitman, and A.C. Schuh. 1995. Failure of blood-island formation and vasculogenesis in Flk-1-deficient mice. Nature (Lond.). 376:62-66.

12. Fong, G.-H., J. Rossant, M. Gertsenstein, and M.L. Breitman. 1995. Role of the Flt-1 receptor tyrosine kinase in regulating the assembly of vascular endothelium. Nature (Lond.). 376:66-70.

13. Senger, D.R., C.A. Perruzzi, J. Feder, and H.F. Dvorak. 1986. A highly conserved vascular permeability factor secreted by a variety of human and rodent tumor cell lines. Cancer Res. 46:5629-5632.

14. Simon, M., H.-J. Gröne, O. Jöhren, J. Kullmer, K.H. Plate, W. Risau, and E. Fuchs. 1995. Expression of vascular endothelial growth factor and its receptors in human renal ontogenesis and in adult kidney. Am. J. Physiol. 268: F240-F250. 
15. Kaipainen, A., J. Korhonen, K. Pajusola, O. Aprelikova, M.G. Persico, B.I. Terman, and K. Alitalo. 1993. The related FLT4, FLT1, and KDR receptor tyrosine kinases show distinct expression patterns in human fetal endothelial cells. J. Exp. Med. 178:2077-2088.

16. Breier, G., U. Albrecht, S. Sterrer, and W. Risau. 1992. Expression of vascular endothelial growth factor during embryonic angiogenesis and endothelial cell differentiation. Development (Camb.). 114:521-532.

17. Peters, K.G., C. De Vries, and L.T. Williams. 1993. Vascular endothelial growth factor receptor expression during embryogenesis and tissue repair suggests a role in endothelial differentiation and blood vessel growth. Proc. Natl. Acad. Sci. USA. 90:8915-8919.

18. Bacic, M., N.A. Edwards, and M.J. Merrill. 1995. Differential expression of vascular endothelial growth factor (vascular permeability factor) forms in rat tissues. Growth Factors. 12:11-15.

19. Bernstein, J., F. Cheng, and J. Roszka. 1981. Glomerular differentiation in metanephric culture. Lab. Invest. 45:183-190.

20. Hanatani, M., Y. Tanaka, S. Kondo, I. Ohmori, and H. Suzuki. 1995. Sensitive chemiluminescence enzyme immunoassay for vascular endothelial growth factor/vascular permeability factor in human serum. Biosci. Biotechnol. Biochem. 59:1958-1959.

21. Shifren, J.L., N. Doldi, N. Ferrara, S. Mesiano, and R.B. Jaffe. 1994. In the human fetus, vascular endothelial growth factor is expressed in epithelial cells and myocytes, but not vascular endothelium: implications for mode of action. J. Clin. Endocrinol. Metab. 79:316-322.

22. Abrahamson, D.R. 1987. Structure and development of the glomerular capillary wall and basement membrane. Am. J. Physiol. 253:F783-F794.

23. Shweiki, D., A. Itin, D. Soffer, and E. Keshet. 1992. Vascular endothelial growth factor induced by hypoxia may mediate hypoxia-initiated angiogenesis. Nature (Lond.). 359:843-845. 